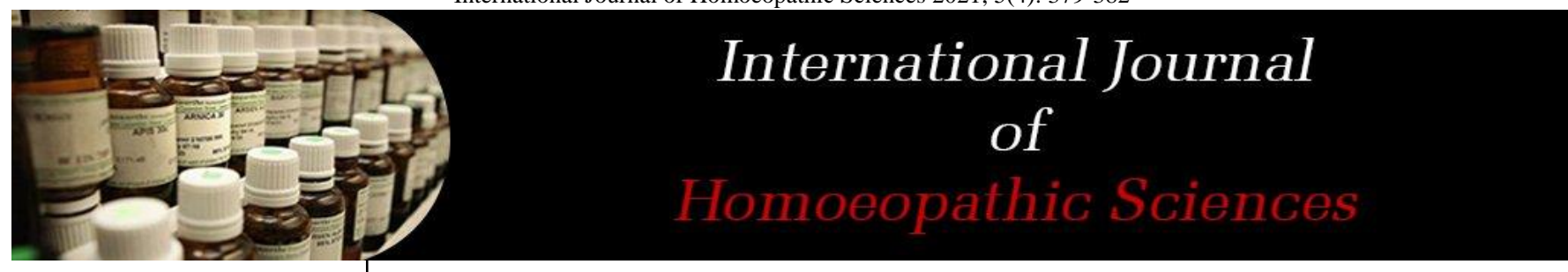

E-ISSN: $2616-4493$

P-ISSN: 2616-4485

www.homoeopathicjournal.com

IJHS 2021; 5(4): 379-382

Received: 14-05-2021

Accepted: 23-07-2021

Dr. Km Om Jee

Assistant Professor,

Department of Obs and Gynae,

Dr. Yadubir Sinha

Homoeopathic Medical College

and Hospital, Laheriasarai,

Darbhanga, Bihar, India
Corresponding Author:

Dr. KM OM JEE

Assistant Professor,

Department of Obs and Gynae,

Dr. Yadubir Sinha

Homoeopathic Medical College

and Hospital, Laheriasarai,

Darbhanga, Bihar, India

\section{Menopause and homoeopathy}

\section{Dr. Km Om Jee}

DOI: https://doi.org/10.33545/26164485.2021.v5.i4f.499

\section{Abstract}

Menopause is a stage of life when a lady stops having her monthly period. It's a normal part of aging and marks the end of reproductive years. During the transition phase a lot of physical, emotional and mental symptoms develop in human body. Homoeopathy is a safe and a definite therapy for women suffering from menopausal symptoms. By using the homoeopathy we can smooth her life easily and manage all the consequences in a well manner.

Keywords: Menopause, lifestyle, HRT, homoeopathy

\section{Introduction}

The menopause is defined as the woman's final menstrual period and the accepted confirmation of this is made retrospectively after 1 year of amenorrhoea. The cause of the menopause is cessation of regular ovarian function ${ }^{[1]}$.

Terms related with menopause-

Menopause: the last menstrual period (LMP).

Perimenopause: time of life from the onset of ovarian dysfunction until 1 year after the last period and the diagnosis of menopause is made. This time is also known as the climacteric.

Postmenopause: all women who have been 1 year since their last period are deemed postmenopausal $^{[1]}$.

Premature menopause: If the menopause occurs at or below the age of 40 it is said to be premature.

Delayed menopause: If the menopause failed to occur even beyond 55 years it is called delayed. The common causes are constitutional, uterine fibroids, diabetes mellitus and oestrogenic tumour of the ovary.

Artificial menopause: Permanent cessation of ovarian function done by artificial means, e.g. surgical removal of ovaries or by radiation is called artificial menopause ${ }^{[2]}$.

Climacteric: Is the phase of waning ovarian activity, and may begin 2-3 years before menopause and continue for 2-5 years after it. The climacteric is thus a phase of adjustment between the active and inactive ovarian function and occupies several years of a woman's life, and it involves physical, sexual and psychological adjustments. This phase covers 5-10 years on either side of menopause ${ }^{[3]}$.

Age: Menopause sets in when the follicular number falls below 1000. Menopause normally occurs between the ages of 45 and 50 years, the average age being 47 years. It is not uncommon, however, to see a woman menstruate well beyond the age of 50 . This delayed menopause may be related to good nutrition and better health. Menopausal age is not related to menarche, race, socioeconomic status, number of pregnancies and lactation, or taking of oral contraceptives. It is however directly associated with smoking and genetic disposition. Smoking induces premature menopause ${ }^{[3]}$.

\section{Pathophysiology}

During climacteric, ovarian activity declines. Initially, ovulation fails, no corpus luteum forms and no progesterone is secreted by the ovary. Therefore, the premenopausal menstrual cycles are often anovulatory and irregular. Later, Graafian follicles also fail to develop, oestrogenic activity is reduced and endometrial atrophy leads to amenorrhoea. Cessation of ovarian activity and a fall in the oestrogen and inhibin levels cause a rebound increase in the secretion of FSH and LH by the anterior pituitary gland.

Patterns of menopause: There are three classic patterns 
- Abrupt cessation of menstruation

- Gradual decrease in both amount and duration. It may be spotting or delayed and ultimately lead to cessation.

- Irregular with or without excessive bleeding. One should exclude genital malignancy prior to declare it as the usual premenopausal pattern ${ }^{[2]}$.

\section{Hormone Levels}

There is $50 \%$ reduction in androgen production and $66 \%$ reduction in oestrogen at menopause. The oestrogen level may remain low at $10-20 \mathrm{pg} / \mathrm{mL}$. Some oestrogen comes from the ovary, but most of it is oestrone (E1) derived from peripheral conversion of androstenedione secreted by the ovary, and its level varies between 30 and $70 \mathrm{pg} / \mathrm{mL}$. The ovary also secretes a small amount of testosterone which causes mild hirsutism at menopause. The FSH appears in high concentration in the urine (more than $40 \mathrm{IU} / \mathrm{l}$ ). E2/E1 ratio maintained over 1 in the premenopausal period is reduced to less than 1 in the menopausal age, causing an oestrogen deficiency state. Oestrogen level of over 40 $\mathrm{pg} / \mathrm{mL}$ exerts bone and cardiotrophic effect, but the level below $20 \mathrm{pg} / \mathrm{mL}$ may predispose to osteoporosis and ischaemic heart disease.

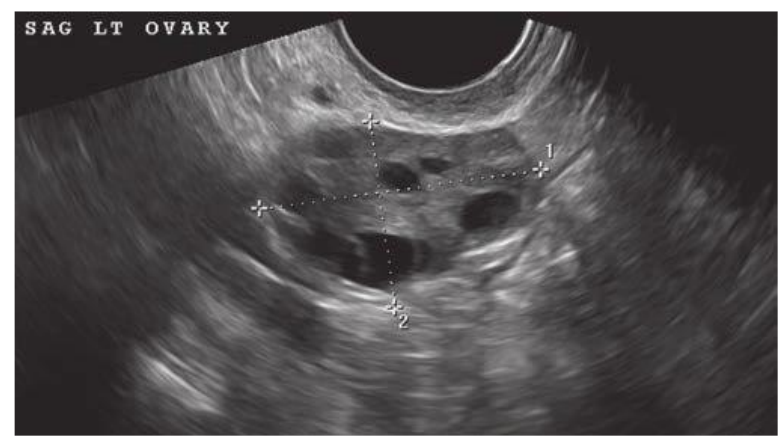

A. In general, premenopausal ovaries have greater volume and contain follicles, which are seen as multiple, small, anechoic smooth-walled cysts.

Fallopian tubes: Show feature of atrophy. The muscle coat becomes thinner, the cilia disappear and the plicae become less prominent.

The uterus: Becomes smaller and the ratio between the body and the cervix reverts to the $1: 1$ ratio. The endometrium becomes thin and atrophic. In some women, however, with high endogenous estrogens, the endometrium may be proliferative or even hyperplastic. The cervical secretion becomes scanty.

The vagina: Becomes narrower due to gradual loss of elasticity. The vaginal epithelium becomes thin. The rugae progressively flatten. There is no glycogen. Doderlein's bacillus is absent. The vaginal $\mathrm{pH}$ becomes alkaline. Maturation index (parabasal, intermediate and superficial cells) is $10 / 85 / 5$.

The vulva: Shows features of atrophy. The labia becomes flattened and the pubic hair becomes scantier. The end result is a narrow introitus.

Breast fat: is reabsorbed and the glands atrophy. The nipples decrease in size. Ultimately, the breasts become flat and pendulous.

\begin{tabular}{|c|c|}
\hline Hormones & Level of hormones \\
\hline $\mathrm{E}_{2}$ & $5-25 \mathrm{pg} / \mathrm{Ml}$ \\
\hline Oestrogen & $20-70 \mathrm{pg} / \mathrm{mL}-$ more in obese women \\
\hline FSH & $>40 \mathrm{mIU} / \mathrm{Ml}$ \\
\hline Androgens & $0.3-1.0 \mathrm{ng} / \mathrm{ml}$ \\
\hline Testosterone & $0.1-0.5 \mathrm{ng} / \mathrm{ml}$ \\
\hline $\mathrm{LH}$ & $50-100 \mathrm{mIU} / \mathrm{Ml}$ \\
\hline Androstenedione & $800 \mathrm{pg} / \mathrm{ml}$ \\
\hline Growth hormone & $\mathrm{Low}$ \\
\hline
\end{tabular}

Diagnosis: The diagnosis of menopause is a largely clinical diagnosis that is made according to symptoms experienced, such as menstrual irregularities and amenorrhoea, and oestrogen deficiency symptoms, such as vasomotor symptoms ${ }^{[1]}$.

\section{Organ changes during menopause}

Ovaries shrink in size, become wrinkled and white. There is thinning of the cortex with increase in medullary components. There is abundance of stromal cells which have got secretory activity.

\section{TVS images of a pre- and postmenopausal ovary ${ }^{[4]}$}

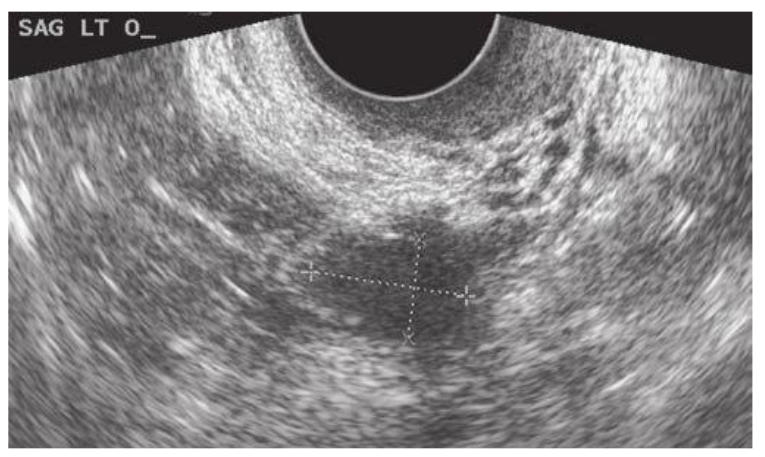

B. In comparison, postmenopausal ovaries have smaller volume and are characteristically devoid of follicular structures.

Bladder and urethra undergo similar changes to those of the vagina. There may be dysuria, frequency, urge or even stress incontinence.

Loss of muscle tone leads to pelvic relaxation, uterine descent and anatomic changes in the urethra and neck of the bladder. The pelvic cellular tissues become scanty and the ligaments supporting the uterus and vagina lose their tone [2].

\section{Symptoms}

Vasomotor symptoms: The characteristic symptom of menopause is 'hot flash'. Hot flash is characterized by sudden feeling of heat followed by profuse sweating. There may also be the symptoms of palpitation, fatigue and weakness. The physiologic changes with hot flashes are perspiration and cutaneous vasodilation. It may last for 1 10 minutes and may be at times unbearable. The thermoregulatory center in association with GnRH center in the hypothalamus is involved in the etiology of hot flash.

Genital and urinary system: Estrogen deficiency produces atrophic epithelial changes in vagina, urinary bladder and the urethra etc. This may cause dyspareunia and dysuria. 
Dyspareunia: Estradiol deficiency leads to vaginal dryness or atrophy.

Vagina: Minimal trauma may cause vaginal bleeding. Dyspareunia, vaginal infections, dryness, pruritus and leucorrhea are also common.

The urinary symptoms are urgency, dysuria and recurrent urinary tract infection and stress incontinence.

Sexual dysfunction: Estrogen deficiency is often associated with decreased sexual desire. This may be due to psychological changes (depression anxiety) as well as atrophic changes of the genitourinary system.

Skin and hair: There is thinning, loss of elasticity and wrinkling of the skin. Skin collagen content and thickness decrease by $1-2 \%$ per year. 'Purse string' wrinkling around the month and 'crow feet' around the eyes are the characteristics. After menopause, there is some loss of pubic and axillary hair and slight balding. This may be due to low level of estrogen with normal level of testosterone.
Psychological changes: There is increased frequency of anxiety, headache, insomnia, irritability, dysphasia and depression. They also suffer from dementia, mood swing and inability to concentrate. Estrogen increases opioid (neurotransmitter) activity in the brain and is known to be important for memory.

Dementia: Estrogen improves cerebral perfusion and cognition.

Osteoporosis and fracture: Following meno-pause there is decline in collagenous bone matrix resulting in osteoporotic changes. Bone mass loss and microarchitectural deterioration of bone tissue occurs primarily in trabecular bone (vertebra, distal radius) and in cortical bones. Bone loss increases to $5 \%$ per year during menopause. Osteoporosis may be primary (Type 1) due to estrogen loss, age, deficient nutrition (calcium, vitamin D) or hereditary. It may be secondary (Type 2) due to endocrine dysfunction ${ }^{[2]}$.

Risk factors for osteoporosis in a women ${ }^{[2]}$.

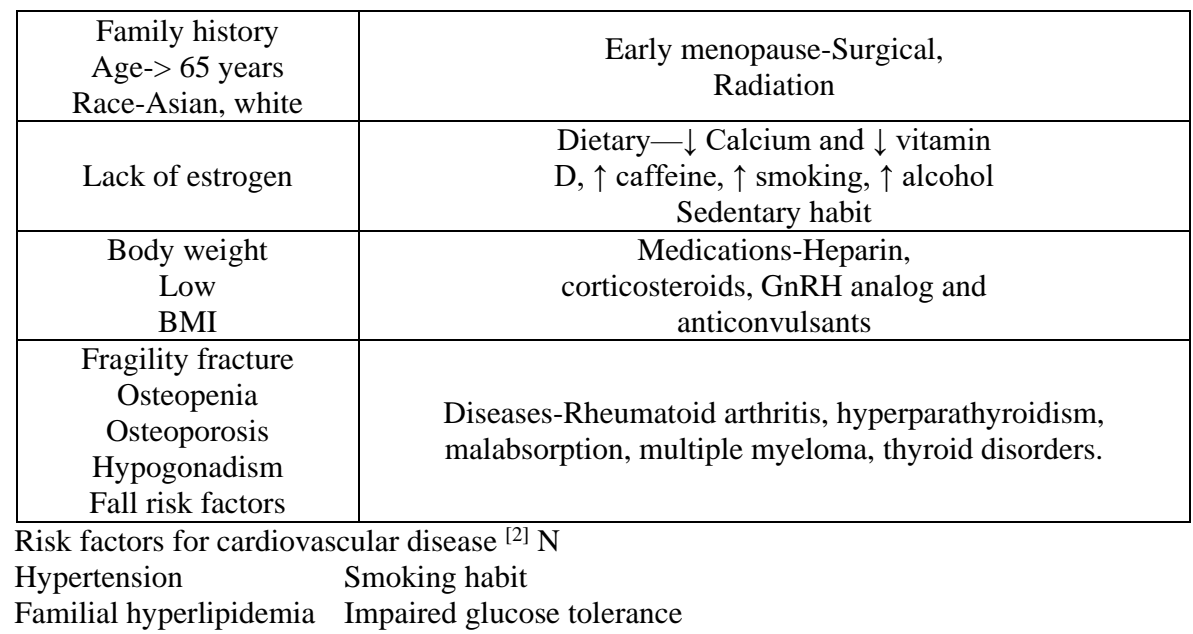

\begin{abstract}
Management ${ }^{[2]}$.
Lifestyle modification: This includes physical activity (walking, jogging and weight bearing exercises), reducing high coffee intake, smoking and excessive alcohol. There should be adequate calcium intake ( $300 \mathrm{~mL}$ of milk), reducing medications that causes bone loss (corticosteroids).
\end{abstract}

Nutritious diet: Balanced with calcium and protein is helpful.

Supplementary calcium: Daily intake of 1-1.5 g can reduce osteoporosis and fracture.

Vitamin D: Supplementation of vitamin D3 (15002000IU/day) along with calcium can reduce osteoporosis and fractures. Exposure to sunlight enhances synthesis of cholecalciferol (vitamin D3) in the skin.

\section{Cessation of smoking and alcohol}

Bisphosphonates prevent osteoclastic bone resorption. It improves bone density and prevents fracture. It is preferred for older women. Women should be monitored with bone density measurement.

Calcitonin inhibits bone resorption by inhibiting osteoclasts. It is a polypeptide hormone. Simultaneous therapy with calcium and vitamin $\mathrm{D}$ should be given. It is given either by nasal spray (200 IU daily) or by injection (SC) (50-100 IU daily). It is used when estrogen therapy is contraindicated. Selective estrogen receptor modulators (SERMs) are tissue specific in action. Of the many SERMs, raloxifene has shown to increase bone mineral density, reduce serum LDL and to raise HDL2 level. Risks of breast cancer and endometrial cancer are therefore reduced.

Soy protein is also found effective to reduce vasomotor symptoms. Soy protein acts as SERM.

Vitamin E reduces hot flash (25\%).

Treatment ${ }^{[2,3,4]}$.

The HT is indicated in menopausal women to overcome the short-term and long-term consequences of estrogen deficiency.

\section{Indications of Hormone Therapy}

Relief of menopausal symptoms

Relief of vasomotor symptoms

Prevention of osteoporosis

To maintain the quality of life in menopausal years.

Special group of women to whom HT should be prescribed

- Premature ovarian failure

- Gonadal dysgenesis

- Surgical or radiation menopause. 


\begin{tabular}{|c|c|}
\hline Benefits of hormone therapy (HT) & Contraindications to hormone therapy \\
\hline $\begin{array}{c}\text { Improvement of vasomotor symptoms (70-80\%) Improvement } \\
\text { urogenital atrophy }\end{array}$ & $\begin{array}{c}\text { Known, suspected or history of breast cancer Undiagnosed genital } \\
\text { tract bleeding Estrogen dependent neoplasm in the body History of } \\
\text { venous thromboembolism or active deep view thrombosis (DVT) } \\
\text { Ancrease in bone mineral density (2-5\%) Decreased risk in } \\
\text { vertebral and hip fractures }(25-50 \%) \text { Reduction in colorectal } \\
\text { cancer }(20 \%) \text { Possibly cardio protection. }\end{array}$ \\
\hline
\end{tabular}

\section{Role of Homoeopathy}

Homoeopathy is very effective in cases of menopause. It is a complete system of medicine, which aim to promote general health by reinforcing the body's own natural healing capacity. It does not treat physical, emotional, mental or even spiritual illness separately; but regards them all as being interconnected ${ }^{[9,10]}$.

Few important homoeopathic medicines that can help us to provide a safe balance of life during menopause ${ }^{[5,6,7,8]}$.

Lachesis: Very important during climacteric and for patients with a melancholic disposition. Ill effects of suppressed discharged. Palpitations, flashes of heat, hemorrhages, headache in the vertex, fainting spells, worse pressure of clothes. Menses too short, too feeble, pains, all relived by the flow. Left ovary very painful and swollen, indurated. Mammae inflamed, bluish. Acts especially well at the beginning and close of menstruation.

Sepia: Tubercular patients with chronic hepatic problems and uterine complaints. Hot flushes at menopause with weakness and perspiration. Ball like sensation in inner parts. Bearing down sensation as if everything would escape through the vulva. Vagina painful, especially during coition.

Sulphuric acid: Hot flushes, followed by perspiration and trembling. Menstruation early and profuse erosion of the cervix in the aged. Easily bleeding. Burning leucorrhoea, often with bloody mucus.

Folliculinum: This is very useful remedy for woman with hormonal symptoms of OCP users. It covers the whole range of physical and mental symptoms around menopause. Obese, hot flushes, night sweats, abdominal heaviness and vaginal dryness are the more common symptoms.

Calc. carb: This is a great constitutional and also antipsoric remedy. Scrofulous constitution and leuco-phelagmatic temperament. Hot swelling of breasts. Excessive sweating and desires for eggs and indigestible things.

Graphitis: Menopausal ladies who are fat, chilly and costive. Mamme swollen and hard. Decided aversion in coitus in both sexes. Heat on face, perspiration.

\section{Conclusion}

The biggest problem during menopause is an unpredictable change in sex hormone levels, especially oestrogen, progesterone and testosterone. HRT is only effective solution for menopause; but many clinical trials showed an increase of breast, ovarian and uterine cancers, heart attacks and strokes by side effect of it. Homoeopathy is a unique treatment that emphasizes on the balance in life. If the homoeopathic medicines prescribed on the basis of constitution, individualization and totality; it can definitely smooth menopausal life with no side effects.

\section{References}

1. Bickerstaff Helen, Louise C Kenney, Gynaecology by ten teachers, $20^{\text {th }}$ edition, CRC press, Boka raton, London; new York, 2017, 105-108.

2. Dutta DC. textbook of Gynaecology, revised and enlarged $7^{\text {th }}$ edition, New Delhi, Jaypee Brothers Medical Publishers (P) Ltd., 2016, 46-52.

3. Bourne \& Howkins, Shaw's Textbook of Gynaecology, $16^{\text {th }}$ edition, New Delhi, Reed Elsevier India P. Ltd. 2015, 65-69.

4. Barbara L. Hoffmann, John O Schorges, Karen D Bradshaw et al. Williams gynecology, Mc Graw hill education 2016, 471-480.

5. Allen HC. Keynote and Characteristics with comparisons of the leading remedies of Materia Medica with Bowel Nosodes, $8^{\text {th }}$ edition, $47^{\text {th }}$ impression. New Delhi B. Jain Publishers P. 1td., 2013;73:142.

6. Boericke W. New manual of Homoeopathic Materia medica with Repertory, $3^{\text {rd }}$ revised and augmented edition, B Jain Publishers P. ltd., New Delhi 2018;129:342.

7. Choudhuri NM. A Study on Materia Medica, $11^{\text {th }}$ Impression, New Delhi B. Jain Publishers P. Itd. 2014;935:1025.

8. Bhanja KC. The Homoeopathic Prescriber, $6^{\text {th }}$ edition, Pressmen Service, Kolkata, 2002, 266.

9. www.pubmed.ncbi.nlm.nih.gov on dated 19/10/2021 at 9:15 pm.

10. www.mysecondspring.ie on dated $19 / 10 / 2021$ at 9:15 pm. 